\title{
ELEVATION MEASUREMENT
}

\section{Elevation measurement at Site Katka-A}

We measured the elevations at Katka-A with a tripod teodolith in relation to a common reference point. We identified the burial depth of the charcoal layer in each kiln by hand-auger drilling and related that depths to the reference point. Vertical error of elevation measurement at Site Katka-A was less than $2 \mathrm{~cm}$, as repeated measurements have shown. The areal relation and distances at this site were measured with compass and measuring tape. The two mangrove root levels are marked by well-preserved Sundari mangrove stumps and their root levels were determined by repeated teodolith measurement at the same precision as for the charcoal layers at the kiln bases.

We traced several tidal ebb cycles during daytime by teodolith measurement. On February 16, 2010, tidal amplitude was $280 \mathrm{~cm}$. A narrow drift line composed of plant fragments and sand documented the highest tidal datum. The spring high-tide which occurred on February 21 was $70 \mathrm{~cm}$ higher than the high tide on February 16.

We choose the modern land surface colonized by mangrove trees of Sundari species (Heritiera fomes) at the edge of the shore as reference datum. This up to 25-m high tree commonly grows in low-saline environments, i.e. in the estuarine zone at the high intertidal level. At Katka, the level of the Sundari root networks is observed just at the reference land surface level and at about $10 \mathrm{~cm}$ above the winter spring high-tide level (thus inundated during the higher summer spring high-tides by about $60 \mathrm{~cm}$ ).

An absolute elevation or one related to an official mean sea level datum had been not possible for this remote site in such a complex, mesotidal coastal system.

\section{Elevation correlation to Site Katka-B}

The elevation of the modern land surface at Katka-B and of the charcoal-marked kiln base was determined in analogy to Katka-A by transferring the coastal Katka-A reference datum through teodolith measurement. However since the mangrove vegetation was partly very dense along this $650-\mathrm{m}$ long track, vertical precision was $\pm 10 \mathrm{~cm}$. The distance to Katka-A of $650 \mathrm{~m}$ was calculated based on own GPS data with a horizontal precision of $5 \mathrm{~m}$ to $7 \mathrm{~m}$ at each site.

\section{Elevation correlation to Site Gawbonia}

The distance of 2,000 m from Katka-A to Site Gawbonia is based on GPS data. The elevation of the two Gawbonia kiln charcoal-bases was related to the February-21 drift line level at Gawbonia. Then the two drift lines of this particular day (winter spring high tide) at Gawbonia and Katka-A were taken for an inter-site correlation to the relative Katka reference datum with an error of less than $2 \mathrm{~cm}$. 


\section{OSL DATING OF QUARTZ}

Optically stimulated luminescence (OSL) on fine grain (4-11 $\mu \mathrm{m})$ and coarse grain (40-63 $\mu \mathrm{m})$ quartz was used to determine the last heating of the kiln walls to $>450{ }^{\circ} \mathrm{C}$. This temperature is supposed to thermally erase the natural luminescence signal of quartz and to reset the luminescence clock to zero. For OSL dating two parameters have to be determined, the dose rate $\left(D_{0}\right.$, in $\left.\mu \mathrm{Gy} / \mathrm{a}\right)$ and the equivalent dose ( $D_{\mathrm{e}}$ in $\left.\mathrm{Gy}\right)$. The luminescence age is then calculated by the equation:

Age (a) = equivalent dose $\left(D_{e}\right.$ in $\left.G y\right) /$ dose rate $\left(D_{0}\right.$ in $\left.\mu G y / a\right)$.

Table DR1: Results of the dose rate determination using high-resolution gamma-ray spectrometry. Water contents were determined from the luminescence samples and are given in relation to dry mass. The water contents used for age calculation are given in column 4 . They are based on the environmental conditions and experimental analyses which were carried out to quantify the maximum water capacity ( $50 \%)$ of the samples.

\begin{tabular}{llcccccc}
\hline $\begin{array}{c}\text { Lab. } \\
\text { Code }\end{array}$ & Sample ID & $\begin{array}{c}\text { Water content } \\
\text { measured } \\
\mathbf{( \% )}\end{array}$ & $\begin{array}{c}\text { Water content } \\
\text { used } \\
\mathbf{( \% )}\end{array}$ & $\begin{array}{c}\text { Sample depth } \\
\text { below } \\
\text { surface } \\
(\mathbf{m})\end{array}$ & $\begin{array}{c}\mathbf{U} \\
(\mathbf{p p m})\end{array}$ & $\begin{array}{c}\text { Th } \\
(\mathbf{p p m})\end{array}$ & $\begin{array}{c}\mathbf{K} \\
\mathbf{( \% )}\end{array}$ \\
\hline C-L3050 & Kat A-2 & 37.8 & $40 \pm 8$ & 0.3 & $3.52 \pm 0.18$ & $18.37 \pm 1.04$ & $2.58 \pm 0.10$ \\
C-L3052 & Kat A-9 & 39.6 & $40 \pm 8$ & 0.3 & $3.35 \pm 0.16$ & $16.39 \pm 0.93$ & $2.39 \pm 0.09$ \\
C-L3053 & Kat A-11 & 37.05 & $40 \pm 8$ & 0.3 & $3.82 \pm 0.19$ & $17.27 \pm 0.99$ & $2.72 \pm 0.11$ \\
C-L3054 & Kat A-13 & 34.5 & $40 \pm 8$ & 0.3 & $3.39 \pm 0.17$ & $17.24 \pm 0.98$ & $2.46 \pm 0.19$ \\
C-L3055 & Kat B-1 & 20.1 & $20 \pm 4$ & 0.3 & $3.86 \pm 0.20$ & $18.91 \pm 1.08$ & $2.68 \pm 0.10$ \\
C-L3058 & GB4-2-3 & 19.4 & $20 \pm 4$ & 1.0 & $3.24 \pm 0.17$ & $18.43 \pm 1.05$ & $2.84 \pm 0.11$ \\
C-L3059 & GB4-2-4a & 13.2 & $20 \pm 4$ & 1.0 & $3.76 \pm 0.20$ & $19.07 \pm 1.09$ & $2.96 \pm 0.11$ \\
\hline
\end{tabular}


Table DR2: SAR-OSL dating results obtained for fine grain and coarse grain quartz. All measurements were carried out on an automated TL-DA 15 Risø TL/OSL Reader with a Hoya U340 filter $(7.5 \mathrm{~mm})$ and a calibrated ${ }^{90} \mathrm{Sr} /{ }^{90} \mathrm{Y}$ beta source. A single aliquot regeneration (SAR) protocol (Murray and Wintle, 2000) with a preheat of $240{ }^{\circ} \mathrm{C} \mathrm{for} 10 \mathrm{~s}$, a cut heat of $220{ }^{\circ} \mathrm{C}$ and an additional hot bleach with $40 \mathrm{~s}$ blue stimulation at $280^{\circ} \mathrm{C}$ after every test dose measurement was used for $D_{\mathrm{e}}$ determination. Validation of the protocol parameters was verified by pre-heat plateau tests and dose recovery test at different temperatures. Average recycling ratios were obtained between 0.99 for Kat A-9 and 1.06 for Kat A-13. Thermal transfer was measured at sample Kat $A-13$ giving a $D_{e}$ below $0.01 \mathrm{~Gy}$.

\begin{tabular}{|c|c|c|c|c|c|c|c|c|c|c|}
\hline $\begin{array}{l}\text { Lab- } \\
\text { code }\end{array}$ & $\begin{array}{c}\text { Sample } \\
\text { ID }\end{array}$ & $\begin{array}{l}\text { Grain } \\
\text { size }\end{array}$ & $\begin{array}{c}\text { Age } \\
\text { model }\end{array}$ & $\begin{array}{c}\text { Over- } \\
\text { dispersion }\end{array}$ & $\begin{array}{l}\text { Number } \\
\text { of discs }\end{array}$ & $\begin{array}{l}\text { Sample } \\
\text { size } \\
(\mathrm{mm})\end{array}$ & $\begin{array}{l}\text { RSD } \\
(\%)\end{array}$ & $\begin{array}{c}D_{e} \\
(G y) \#\end{array}$ & $\begin{array}{l}\text { OSL Age } \\
\text { (a) }\end{array}$ & $\begin{array}{c}D_{0} \\
(\mu G y / a)\end{array}$ \\
\hline C-L3050 & Kat A-2 & $40-63$ & CAM & 26.8 & $72 / 44$ & 1 & 31.5 & $1.14 \pm 0.07$ & $315 \pm 40$ & $3.59 \pm 0.35$ \\
\hline C-L3050* & Kat A-2 & $40-63$ & CAM & 8.5 & $6 / 6$ & 8 & 9.4 & $1.08 \pm 0.07$ & $300 \pm 35$ & $3.59 \pm 0.35$ \\
\hline C-L3052 & Kat A-9 & $4-11$ & CAM & 11.3 & $16 / 10$ & 9 & 15.6 & $1.32 \pm 0.11$ & $330 \pm 40$ & $3.98 \pm 0.37$ \\
\hline C-L3053 & $\begin{array}{l}\text { Kat A- } \\
11\end{array}$ & $40-63$ & CAM & 21.6 & $48 / 38$ & 1 & 26.9 & $1.08 \pm 0.07$ & $295 \pm 35$ & $3.68 \pm 0.37$ \\
\hline C-L3054 & $\begin{array}{l}\text { Kat A- } \\
13\end{array}$ & $40-63$ & CAM & 11.3 & $48 / 37$ & 1 & 13.1 & $1.06 \pm 0.06$ & $310 \pm 35$ & $3.42 \pm 0.35$ \\
\hline C-L3055 & Kat B-1 & $4-11$ & COM & 1.06 & $16 / 15$ & 9 & 3.09 & $1.38 \pm 0.07$ & $280 \pm 25$ & $4.97 \pm 0.42$ \\
\hline C-L3058 & $\begin{array}{l}\text { GB4-2- } \\
3\end{array}$ & $4-11$ & $\mathrm{COM}$ & 0.59 & $16 / 16$ & 9 & 2.43 & $1.31 \pm 0.07$ & $270 \pm 25$ & $4.86 \pm 0.39$ \\
\hline C-L3059 & $\begin{array}{l}\text { GB4-2- } \\
4 a\end{array}$ & $4-11$ & $\mathrm{COM}$ & --- & $16 / 16$ & 9 & 1.92 & $1.30 \pm 0.07$ & $250 \pm 25$ & $5.15 \pm 0.42$ \\
\hline
\end{tabular}

$\mathrm{RSD}=$ relative standard deviation; ${ }^{*}=$ same sample material as C-L3050 but $8 \mathrm{~mm}$ discs measured to verify the resetting of the OSL signal; COM = common age model, CAM = central age model (Galbraith et al. 1999); ${ }^{+}=$number of discs measured and used for $D_{\mathrm{e}}$ determination, \# = rejection criteria for $D_{\mathrm{e}}$ determination $15 \%$ recycling ratio, $10 \%$ max. test dose error, $10 \%$ max palaeodoses error. The cosmic contribution to the dose rate was calculated for sampling depth and a-values of $0.035 \pm 0.02$ (Rees-Jones, 1995) were used. Fine grain $D_{e}$ values and ages were calculated with the "AGE" software by R. Grün (version 1999) which includes the dose conversion factors by Adamiec and Aitken (1998). "ADELE 1.06" software by D. Degering was used for the 40-63 $\mu \mathrm{m}$ fraction.

\section{References}

Adamiec, G., Aitken, M.J., 1998. Dose-rate conversion factors: update. Ancient TL, 16, 3749.

Frechen, M, Schweitzer, U., Zander, A., 1996. Improvements in sample preparation for the fine grain technique. Ancient TL, $14,15-17$.

Galbraith, R.F., Roberts, R.G., Laslett, G. M., Yoshida, H. and Olley, J. O. Optical dating of single and multiple grains of quartz from Jinmium rock shelter, northern Australia: Part I, experimental design and statistical models, Archaeometrie, 41, 339-364, 1999.

Murray, A.S., Wintle, A.G., 2000. Luminescence dating of quartz using an improved singlealiquot regenerative-dose protocol. Radiation Measurements 32, 57-73.

Rees-Jones J (1995) Optical dating of young Sediments using fine-graine -quartz. Ancient TL 13/2, 9-14. 